Research Article

\title{
Evaluation of the wound healing effect of Jasminum grandiflorum by wound contraction studies and wound breaking strength
}

\author{
Ravishankar $\mathbf{M}^{1}$, Jagadeesh $\mathbf{K}^{2}$, Shreenivas P. Revankar ${ }^{2 *}$
}

${ }^{1}$ Professor and Head, Department of Pharmacology, Adichunchanagiri Institute of Medical Sciences, BG Nagar, Bellur, Karnataka, India ${ }^{2}$ Department of Pharmacology, Shimoga Institute of Medical Sciences, Shimoga-577201, Karnataka, India

Received: 31 October 2013

Accepted: 13 November 2013

*Correspondence to:

Dr. Shreenivas P. Revankar,

Email: sprevankar@yahoo.com

(C) 2014 Ravishankar M et al. This is an open-access article distributed under the terms of the Creative Commons Attribution Non-Commercial License, which permits unrestricted noncommercial use, distribution, and reproduction in any medium, provided the original work is properly cited.

\begin{abstract}
Background: Wound is a common process leading to inflammation and healing process. Jasminum grandiflorum is a plant widely grown in Karnataka and is mention in ancient medical systems to promote healing. So the study was taken up to confirm the anti-inflammatory effect of the plant.

Methods: Excision and incision wound models in albino rats were used to study the wound healing effect. It was mainly studied by the degree of epithelisation at various intervals and compared with control group. The strength of the wound was assessed by its wound breaking strength at the end.

Results: It was found that jasmine extract increased the degree of epethelisation and thus promoting wound healing. It was also found that the wound breaking strength was more in the drug treated group compared to normal.
\end{abstract}

Conclusions: Jasminum grandiflorum leaf extract is known to have wound healing property.

Keywords: Wound healing, Jasminum grandiflorum, Incision model, Excision model, Wound contraction, Wound breaking strength

\section{INTRODUCTION}

Wound is a medical problem faced by man since his very existence. Healing is the retraction of integrity to the injured tissue. In pathological context it refers to the replacement of destroyed tissue by a living tissue. The different stages involved in the wound healing process are inflammation, wound contraction repair and regeneration. ${ }^{1}$

Inflammation is a protective response intended to eliminate the initial cause of injury (microbes or toxins) and necrotic cells ${ }^{2}$. Based on the duration inflammation is of two types acute and chronic. Acute inflammation is of short duration and chronic of longer duration. The five cardinal signs of inflammation are rubor, calor, dolor, tumor and function laesa.,

The inflammatory phase provides initial tensile strength to wound. Wound contraction usually starts 2 to 3 days after wound and is complete by 14 days. The wound is reduced to approximately $80 \%$ of the original size. ${ }^{4}$ Contraction results in faster healing, if contraction is prevented, healing is slowed and results in large ugly scar. Repair is an orderly process in which wound is eventually replaced by scar ${ }^{5}$. Regeneration is replacement of tissues and cells with that of identical function and morphology. The process of wound healing involves granulation tissue formation, angiogenesis, and deposition of collagen extracellular matrix; collagen synthesis, collagen turnover and scar formation. ${ }^{6,7}$

Various factors which effect wound healing process are classified into local, systemic and specific factors. The local factors are type, size and location of wound; vascular supply, infection, movement, radiation, UV light etc. Systemic factors include circulatory status, infection, metabolic status, malnutrition and effect of hormones 8 . Cytokines or growth factors EGF (epidermal growth factor), TGF, VEGF, IGF and FGF are some of the 
specific factors which influence the wound healing process. ${ }^{9}$

There are various models to monitor the wound healing process. Rabbits, rats and mice are some of the experimental animals used to study the wound healing process, among these albino rats are the most commonly used $^{10}$. The wound healing process is monitored by different parameters namely physical, mechanical, histopathology and biochemical. In the physical attribute we see for the contraction and epethelisation process. Histological study involves the microscopic features like inflammatory cells, collagen, fibroblasts and epethelisation. Biochemical attribute includes the mucopolysaccharides and collagen content. Finally the quality of healing process is analyzed by wound breaking strength which forms the mechanical parameter. Jasminum grandiflorum is commonly called as Jasmine in English, Cameli in Hindi and Mallige in Kannada. The plant is widely distributed in Asia, Africa and Australia. In India grows all over in forests and also cultivated. Almost all parts of the plant is known to have medicinal value $^{11}$. There are varieties of herbal preparation for wound healing in the folklore medicine like erytrina indica, lantana camarairidax, procumbens, circumm longa Linn etc. one among them is crushed leaves of Jasminum grandiflorum, crushed leaves of the plant are advocated in number of ayurvedic literatures. Hence present study was undertaken to establish the traditional claim, and to study the wound healing effect of Jasminum grandiflorum leaves in albino mice. ${ }^{12}$

\section{METHODS}

The study was carried out in the Department of Pharmacology JJ Medical College Davangere. The healthy adult albino rats of either sex weighing 100 to 150 gms of more than 2 months age which were inbreed in the central animal house were housed at suitable temperature, ventilation and nutrition. The animals were divided into four groups of six animals in each. ${ }^{10}$ The fresh leaves of Jasminum grandiflorum were collected from the botanical garden of Ashwini Ayurvedic Medical College after confirmation from botanist. The leaves were washed, cleaned and wiped dry. Then it was ground fine in a grinder by adding water and a paste was prepared. The paste was used for application on the wounds. ${ }^{13}$ The wound models chosen for the study were excision and resutured incision wound models. The three attributes namely physical, mechanical and histological features were observed and studied. The animals were depilated on the dorsal surface before wounding they were caged individually with free access to water and food then the animals were starved for $12 \mathrm{hrs}$ with only free access to water prior to wounding. Wounding was performed under light ether anesthesia. Drug application was started from day of wounding. Paste was applied on the whole surface of the wound twice daily at $10 \mathrm{AM}$ and $4 \mathrm{PM}$. The duration of treatment varied as per wound model. All control animals received equal volume of normal saline.
Excision wound model: An impression was made on the depilated thoracic surface $2 \mathrm{cms}$ behind the ears and $1 \mathrm{~cm}$ away from the vertebral column, by using a round seal of $2 \mathrm{cms}$ diameter as used by Hunt and coworkers. ${ }^{14}$ The full thickness of impression area was excised to obtain a wound area of 31.4 sq.mm. Homeostasis was obtained by blotting the wound with cotton swab soaked in normal saline. The wound on the right side was to assess the test compound and wound on the left was taken as the control.

The physical attributes of wound healing namely wound closure (contraction and epethelisation time) were studied in this model. ${ }^{7}$ Contraction which mainly contributes for wound closure in the first two weeks was studied by tracing the raw wound on a tracing paper on the wounding day followed by 4, 8, 12, 16 days and subsequently on every alternative day, till complete epethelisation (fall of scab) occurred. Wound area was measured by retracing the wound on a millimeter scale graph paper.

The degree of wound healing was calculated as percentage closure in wound area from original wound area. The mean and standard error values were calculated. The number of days required for complete epethelisation was noted.

Resutured incision model: Here the two paravertebral linear incisions of $6 \mathrm{~cm}$ each were made through the entire thickness of the skin with the help of sterile sharp blade under light ether anesthesia as described by Ehrlich and hunt15. Care was taken to see that the incisions were at least $1 \mathrm{~cm}$ lateral to the vertebral column. The wounds were closed by means of interrupted sutures placed at a equidistant point about $1 \mathrm{~cm}$ apart, using 4-zero silk thread and straight round body needles. Wounds were then mopped with cotton swabs soaked in $70 \%$ alcohol. The wound on right side was used to assess the test compound and wound on left side was taken as control.

Removal of sutures was done on the $8^{\text {th }}$ post wounding day. Wound breaking strength was determined on the 10th post wounding day $^{16}$, as described below. The anaesthetized animal was secured to the operation table in its natural position and lines were drawn on either side of the wound margin on adjacent normal skin leaving about $5 \mathrm{~mm}$ from wound on both the ends. Two Allis forceps were firmly applied on the lines facing each other; the forceps on the sides was hooked to metal rod fixed firmly to the operation table. The forceps was tied with a string, which ran over a pulley. To the other end of the string, serial measuring weights in ascending order were added. The basal weight added to the string was $50 \mathrm{gm}$ and the weight was gradually increased. As soon as the wound gaping was observed, the weights were immediately removed and total weight was noted down.

The wound breaking strength was expressed as the minimum weight at which the wound started to gape. Three such recordings were made for a given incision 
wound and the procedure was repeated on the other side. $^{16}$

\section{RESULTS}

The result of the present study was grouped under the following headings.

- Percentage closure of excision wound on different days (Table 1).

Method: Excision wound Number of animals used: 12 animals

Animals: Albino rats

Route of drug administration: Local application

Weight: $100-150$ gms

Initial wound size: $31.4 \mathrm{~mm}^{2}$

Table 1: Percentage closer of excision wound on different days.

\begin{tabular}{|c|c|c|c|c|c|c|}
\hline \multirow{2}{*}{ Groups } & \multirow{2}{*}{ Drugs } & \multirow{2}{*}{ n } & \multicolumn{4}{|c|}{ Percentage closure (Mean \pm SE) } \\
\hline & & & Day 4 & Day 8 & Day 12 & Day 16 \\
\hline 1 & Control & 12 & $38.5 \pm 4.61$ & $74.3 \pm 1.58$ & $85.7 \pm 1.53$ & $97.1 \pm 0.38$ \\
\hline \multirow[t]{3}{*}{2} & Jasminum grandiflorum & 12 & $47.4 \pm 5.04$ & $83.4 \pm 1.78$ & $96.9 \pm 0.42$ & $100.0 \pm 0.0$ \\
\hline & t- value* & & 2.19 & 3.65 & 7.10 & 7.69 \\
\hline & Significance & & $\begin{array}{l}\mathrm{p}<0.05 \\
\text { Significant }\end{array}$ & $\begin{array}{l}\mathrm{p}<0.01 \\
\text { Significant }\end{array}$ & $\begin{array}{l}\mathrm{p}<0.001 \\
\text { Highly } \\
\text { significant }\end{array}$ & $\begin{array}{l}\mathrm{p}<0.001 \\
\text { Highly } \\
\text { significant }\end{array}$ \\
\hline
\end{tabular}

Note: Significant enhancement of wound closure in the wounds treated with Jasminum grandiflorum when compared to the control. *Students't- test

- Time taken for $50 \%$ wound contraction (Table 2) - Time taken for complete epithelisation (Table 3)

Method: Excision wound Number of animals used: 12 animals

Animals: Albino rats Route of drug administration: Local application

Weight: $100-150$ gms Initial wound size: $31.4 \mathrm{~mm}^{2}$

Table 2: Time taken for 50 percent wound contraction.

\begin{tabular}{|llll|}
\hline Groups & Drugs & $\mathbf{n}$ & Wound contraction days (WC-50\% Days) (Mean \pm SE) \\
\hline 1 & Control & 12 & $5.7 \pm 0.33$ \\
\hline 2 & Jasminum Grandiflorum & 12 & $4.5 \pm 0.40$ \\
\hline & t- value* & 2.31 \\
\hline & Significance & $\mathrm{P}<0.05$ Significant \\
\hline
\end{tabular}

Note: Early achievement of 50\% wound contraction in wounds treated with Jasminum grandiflorum when compared to control. *Students't- test

Method: Incision wound Number of animals used: 6animals

Animals: Albino rats Route of drug administration: Local application

Weight: $100-150$ gms Initial wound size: $6 \mathrm{cms}$

Table 3: Time taken for complete epithelisation.

\begin{tabular}{|llll|}
\hline Groups & Drugs & No. of incisions & $\begin{array}{l}\text { Wound breaking strength } \\
\text { in grams (Mean } \pm \text { SE) }\end{array}$ \\
\hline 1. & Control & 6 & $452.50 \pm 82.97$ \\
\hline 2 & Jasminum grandiflorum & 6 & $485.00 \pm 85.50$ \\
\hline Wilcoxon's signed rank test & & $\mathrm{T}=0 *(* \mathrm{~T}$ is lesser of the ranks) (Table value $=2.1)$ \\
\hline Significance & & $\mathrm{P}<0.05$ Significant & \\
\hline
\end{tabular}

Note: Significant increase in the wound breaking strength in Jasminum grandiflorum treated wounds as compared to the control

- Histopathological findings of wound biopsy.

- Wound breaking strength of 10 days old skin incision wound.

\section{DISCUSSION}

Wound healing is a complex phenomenon involving a number of processes, A proper healing of the wound is 
essential for restoration of the anatomical continuity and the functional state. There are many folklore medicines and indigenous drugs which are claimed to promote wound healing among them leaves of Jasminum grandiflorum is one. This study was done to find the effectiveness of the paste prepared from Jasminum grandiflorum leaves, in promoting the wound healing using different standard parameters. As can be established from the results the test drug has shown to accelerate the wound healing process. So also other parts of the plant extract may also have the wound healing property and the need to be studied specifically.

In the above study incision and excision wound models were used. The excision wound model 1 was used to study the time taken for $50 \%$ wound contraction and complete epethelisation. Excision model 2 was used to study the histopathological features of the wound on different days. Resutured incision wound model, to measure the wound breaking strength of the 10 day old incision wound. In all the models it was found Jasminum grandiflorum significantly improved the healing process. The other wound healing models can be tried upon as an improvement over the study. In the above study two parameters were studied namely physical and mechanical but biochemical parameter was not carried out, so this can also be carried out to substantiate the results for accuracy. There is enough scope to evaluate for the wound healing process in the burn wounds.

\section{CONCLUSION}

The leaves of Jasminum grandiflorum have been advocated for variety of wounds in the body in a number of ayurvedic literatures. Hence a study was undertaken to estimate its wound healing efficacy. Jasminum grandiflorum leaves promoted wound healing by improving the early inflammatory process, by enhancing wound contraction and by promoting an early epethelisation when compared with control in albino rats. Further studies would be required to substantiate the wound healing effect of Jasminum grandiflorum.

Funding: No funding sources

Conflict of interest: None declared

Ethical approval: Approval was taken from the institutional animal ethics committee

\section{REFERENCES}

1. Cotran, Ramzi S, et al. Robbins pathologic basis of disease, $5^{\text {th }}$ edition Philadelphia, Pennsylvania: W. B. Saunders Company. 1994:51-92.
2. Cohnhein J. Lectures in general pathology (Translated by MCknee A. D from the second German edition, Vol. 1). London: New Sydenham Society -1889 .

3. Damjanov Ivan, James Linder. Anderson's pathology, $10^{\text {th }}$ edition, Vol. 1, St. Louis, Missouri: Mosby - Year Book, Inc. 1996:416-47.

4. Albert N. J. Oct. 1993 "wound healing". Dermatological Clinics. 11:4:629-808.

5. Knappa T.R., Daniel J.R. and Kaplan G. N. 1977 "Pathologic scar formation". American Journal of Pathology". 47-70.

6. Rissan W. 1977 "Mechanisms of angiogenesis". Nature. 386:671

7. Montandon D., D'Andriran G., and Gabbiani G. 1977 "The mechanism of wound contraction and epethelisation" Clinical Plastic Surgery. 4:325.

8. Ehrlich P., Tarver H. and Hunt T. K. "Effect of vitamin A, Glucocorticoids on inflammation and collagen synthesis". Annals of surgery. 1973;222: $117-26$.

9. Drovak H.F. "Vasular permeability factor/ vascular endothelial growth factor, microvascular hyperpermeability and angiogenesis". American Journal of Pathology. 1995;146:1029.

10. Morton J. J. P and Malone M. H "Eveluation of vulanaray activity by an open wound procedure in rats". Archives: International Pharmacodynamics. 1972;196:117 - 26.

11. Nadkarni K. M., Indian Materia Medica. $3^{\text {rd }}$ Edition, Rev and Enl, Vol. I, Mumbai: Popular. 1976:701-2.

12. Theodore Cooke. The flora of the presidency of Bombay. Reprinted under the authority of the Government of India. Botanical survey of India. Volume II, Calcutta. 1904:171.

13. Warrier P. K., Nambiar V. P. K., Ramankutty C., Vaidyarathnam P. S Varier's Arya Vyadyasala, Indian Medicinal plants, Vol. 3. Kottakat: Orient Longman. 1996:249-53.

14. Ehrlich P. and Hunt T. K. Aug "The effects of cortisone and anabolic steroid on the tensile strength of healing wounds". Annals of Surgery. 1969:203-6.

15. Ehrlich HP, Grislis, Hunt TK. Evidence for involvement of microtubules in wound certificate. American Journals of Surgery. 1977;133:706-9.

16. Levenson SN, Geever E, Gowley LV, et al. The healing of rat skin wounds. Annals of Surgery. 1965;161(2):293-308.

doi:10.5455/2319-2003.ijbcp20140205

Cite this article as: Ravishankar M, Jagadeesh K, Revankar SP. Evaluation of the wound healing effect of Jasminum grandiflorum by wound contraction studies and wound breaking strength. Int J Basic Clin Pharmacol 2014;3:66-9. 